\title{
Legislación urbana e incapacidad Directiva de los gobiernos municipales sobre el territorio: el caso del Asentamiento Humano Irregular EI Tigre II
}

\section{Urban legislation and directive inability of local governments on the territory: the case of Irregu- lar Human Settlement EI Tigre II}

AUTOR: Roberto Arias de la Mora y José Eduardo Gutiérrez Roque

Resumen: El presente artículo estudia a profundidad los incentivos políticos que enfrentan los gobiernos municipales bajo un contexto metropolitano que motivan regulaciones laxas de los procesos inmobiliarios, aumenta la polarización del uso de la tierra y, consecuentemente, incrementa la polarización del ingreso y de la actividad económica lo cual a su vez agravan los problemas de recaudación y provisión de bienes públicos que enfrentan los gobiernos municipales ubicados en la periferia de una zona metropolitana. En particular, presenta los avances en torno al caso de estudio El Trigre II que forma parte de una línea de investigación más amplia acerca de los asentamientos humanos irregulares en el Área Metropolitana de Guadalajara. Los hallazgos sugieren que la naturaleza reactiva de la legislación en materia urbana ha motivado un grave problema de incapacidad directiva de los gobiernos municipales frente al fenómeno metropolitano.

Palabras clave: Legislación Urbana, Asentamientos Humanos Irregulares, Incapacidad Directiva de los Gobiernos, Fenómeno Metropolitano.

Abstract: This article examines in depth the political incentives that local governments face in a metropolitan context that motivate lax regulations in property processes, increase the polarization of land use and, consequently, increase the polarization of income and economic activity which in turn exacerbates the problems of collection taxes and provision of public goods that municipal governments located on the periphery of a metropolitan area face. In particular, this article presents the case study El Tigre II. This case is part of a broader case study about the irregular communities in the metropolitan area of Guadalajara. The findings suggest that the reactive nature of the urban legislation has led to a serious policy failure of municipal governments facing the "metropolitan phenomenon".

Keywords: Urban Legislation, Irregular Settlements, Disability Policy Governments, Metropolitan Phenomenon. 


\section{Introducción}

El estudio de caso que se presenta en este artículo forma parte de una investigación más amplia sobre el fenómeno de los asentamientos humanos irregulares (AHI en lo sucesivo), como una expresión particular de la urbanización expansiva, dispersa e insustentable que se ha configurado en torno a lo que formalmente se reconoce hoy como el Área Metropolitana de Guadalajara.

Si bien es cierto que algunas investigaciones recientes han mostrado cómo los incentivos políticos que enfrentan los gobiernos municipales bajo un contexto metropolitano, motivan regulaciones laxas de los procesos de desarrollo inmobiliario, aumenta la polarización del uso de la tierra y, consecuentemente, incrementa la polarización del ingreso y de la actividad económica, lo cual a su vez agravan los problemas de recaudación y provisión de bienes públicos que enfrentan los gobiernos municipales ubicados en la periferia de una zona metropolitana (Caro, Gatica y Ruiz, 2013), este trabajo pretende estudiar a profundidad la manera en que esta tendencia ampliamente reconocida, se concretó históricamente en un municipio específico del Área Metropolitana de Guadalajara. El énfasis del artículo subraya la manera en que la condición reactiva en la evolución de la legislación urbana frente al fenómeno metropolitano (Arias, 2013), ha motivado una incapacidad directiva de los gobiernos municipales frente los procesos extensivos de urbanización que se manifiestan sobre sus territorios.

Para ello, se presenta algunos de los avances de investigación que, desde una perspectiva de política pública, estudia el caso del $\mathrm{AHI}$ denominado el Tigre II que se localiza en el municipio de Zapopan, Jalisco. El artículo se organiza en tres secciones. En primer término se introduce al lector a la definición del problema de la legislación urbana a partir de la discusión pública en torno a la nueva Ley General de Ciudades y Territorio. En un segundo momento se describe desde una perspectiva cronológica el nacimiento y evolución del AHI objeto de este estudio y finalmente se plantean algunas reflexiones preliminares a manera de conclusión. 


\section{Definiendo el problema en torno a la legislación urbana: su incapacidad de imponer sanciones.}

En virtud de que el presente artículo se inscribe metodológicamente en la orientación aplicada del análisis de políticas públicas, ${ }^{1}$ la cual enfatiza la posibilidad de asumir algunos criterios provenientes de la argumentación sostenida durante la discusión y debate de la cuestión pública que se pretende estudiar, su punto de partida se centra en la naturaleza punitiva de la legislación urbana que actualmente se viene discutiendo en el seno del Congreso de la Unión.

En el contexto de la eventual aprobación de la Ley General de Ciudades y el Territorio, en efecto, una nota periodística enfatizó la naturaleza punitiva de dicha legislación, argumentando que de haberse aprobado dicha Ley hace diez años "el penal de puente grande se habría llenado de funcionarios vanales que autorizaron fraccionamientos en zonas irregulares o de riesgo en municipios como Tlajomulco, Zapopan o El Salto" (Milenio Jalisco, 14/04/15). Y es que de acuerdo con la publicación, por primera vez en la historia se contempló que en el Código Penal Federal se incorporara una sanción por conductas ilícitas vinculadas con el desarrollo urbano irregular al imponer a los funcionarios públicos "de dos a siete años de prisión, multa de treinta a tres cientas veces el salario mínimo diario vigente en el Distrito Federal en el momento de cometerse el delito y destitución o inhabilitación de dos a siete años para desempeñar otro empleo, cargo o comisión públicos" (Milenio Jalisco, 14/04/15).

Si bien es cierto que la fundamentación teórica en que se apoya este tipo de prescripciones y tratamiento normativo no es reciente (Becker, 1968), y más aún, hoy se reconoce al análisis económico del derecho ${ }^{2}$ como una disciplina con una contribución e influencia importante en el contexto del pensamiento jurídico contemporáneo, lo cierto es que su incidencia política puede considerarse más bien marginal en el ámbito de las políticas urbanas. ${ }^{3}$

\footnotetext{
${ }^{1}$ Este trabajo se inscribe en la idea de que el análisis de políticas públicas al menos comparte tres rasgos básicos para cualquiera de las disciplinas o los métodos con los que se emprenda: su objeto de estudio, su orientación aplicada y práctica y su autocontención. (Cfr. Merino, 2010:10).

${ }^{2}$ Para una revisión sobre el campo interdisciplinario del derecho y la economía o análisis económico del derecho se sugiere revisar (Roemer, 1994).

${ }^{3}$ En virtud de que el ámbito de las políticas urbanas tienen que ver esencialmente con la manera en
} 
En particular, la discusión en torno a la referida Ley General de Ciudades y Territorio se fundamenta en el clásico supuesto teórico que asume la manera en que:

Un agente económico racional decide ceñirse a una regla dada, o cumplir con una reglamentación, dependiendo del valor que espera obtener si rompe las reglas y se sale con la suya. Mientras mayor sea la probabilidad de ser sorprendido rompiendo una regla o más grande sea el castigo si lo descubren, menor es el valor esperado de un comportamiento delincuente y, por eso, menor la probabilidad de que el agente se arriesgue a romper las reglas (Lüders y Rubio, 1999:135-36).

Sin demérito de la validez de la fundamención económica que subyace al debate actual en torno a nueva legislación urbana, el caso de estudio que se expone a continuación revela cómo al no resolverse satisfactoriamente la tensión que típicamente suele presentarse entre las condiciones impuestas por lo que Matin Rein y Francine F. Rabinovitz definieron como los imperativos legal, racional-burocrático y consensual presentes en la implementación de políticas (Aguilar, 1996), puede resultar en una escasa capacidad y eficacia directiva de los gobiernos ${ }^{4}$ como la que, a la luz de la siguiente historia, parecen padecer los gobiernos municipales para regular los procesos de urbanización de sus territorios.

\section{Un intento fallido de regularización: el caso de AHI El Tigre II lo- calizado en el municipio de Zapopan, Jalisco, México.}

\section{II.1 El contexto demográfico y urbanístico actual de EI Tigre II.}

El AHI denominado "El Trigre II" se compone por una población total de 760 personas, de las cuales únicamente 316 pueden considerarse como económicamente activas y con capacidad para proveer el sustento de las 245 familias que actualmente componen dicho asen-

que se distribuyen en el territorio tanto los espacios productivos como los habitacionales, su naturaleza tiene que ver esencialmente con la regulación pública de la división económica y social del espacio (Bruguè y Gomá, 1998:180).

4"La cuestión acerca de la capacidad y eficacia directiva de los gobiernos se ha colocado en el centro de las disciplinas que estudian el gobierno y en el corazón de la preocupación ciudadana. [...] La lista de los defectos directivos de los gobiernos puede extenderse y pormenorizarse, pero su común de- 
tamiento. En la siguiente gráfica se muestra la densidad poblacional:

\section{Gráfica 1. Densidad Poblacional.}

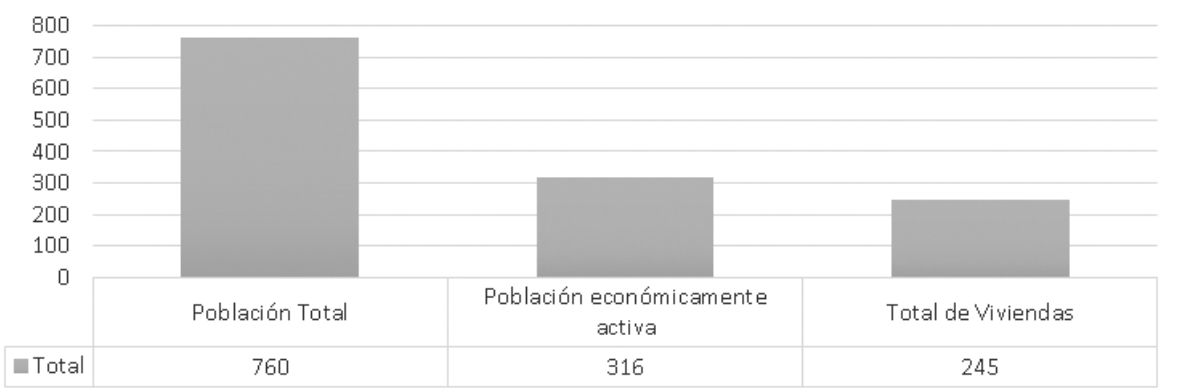

Fuente: Elaboración propia con datos del COEPO con base en el XII Censo de Población y Vivienda 2000.

La estructura urbana del AHI se configura a partir de 36 manzanas compuesta por lotes de terreno que, en promedio, tienen una superficie de 115 metros cuadrados, con construcciones de dos pisos en su gran mayoría dedicadas a la vivienda unifamiliar en su totalidad. El trazo urbano se conforma a partir de vialidades bien definidas que en su mayoría no dispone de algún tipo de cinta asfáltica -apenas el 30 por ciento de las vialidades cuenta con el empedrado conocido como "zampeado"-, y en su totalidad carecen de banquetas.

Por la manera irregular en la que se fue estableciendo el asentamiento humano, bajo una normatividad que permitía un uso del suelo para habitación horizontal en densidad alta $(\mathrm{H} 4-\mathrm{H})$, se carecen de áreas verdes o espacios dedicados al esparcimiento cívico dentro de su configuración urbana. El uso habitacional fue restringido a partir del 6 de marzo de 2008, fecha en que se estableció por primera vez una franja de amortiguamiento para mitigar los efectos de la urbanización sobre las áreas naturales. Dicha delimitación se realizó al amparo de la publicación del decreto 22170/LVIII/08 del Congreso del Estado de Jalisco, que declaró formalmente como Área Natural Protegida (ANP), bajo la categoría de Área Municipal de Protección Hidrológica, la zona del corredor natural integrado por el Bosque Nixticuil, San Esteban y El Diente.

nominador es la ineficacia relativa del gobierno en el cumplimiento de las funciones públicas y en la realización de los objetivos de importancia social, con el resultado de que ha crecido el escepticismo en la capacidad directiva de los gobiernos. (Aguilar, 2010:5) 


\section{Mapa 1. Delimitación del AHI "EI Tigre"}

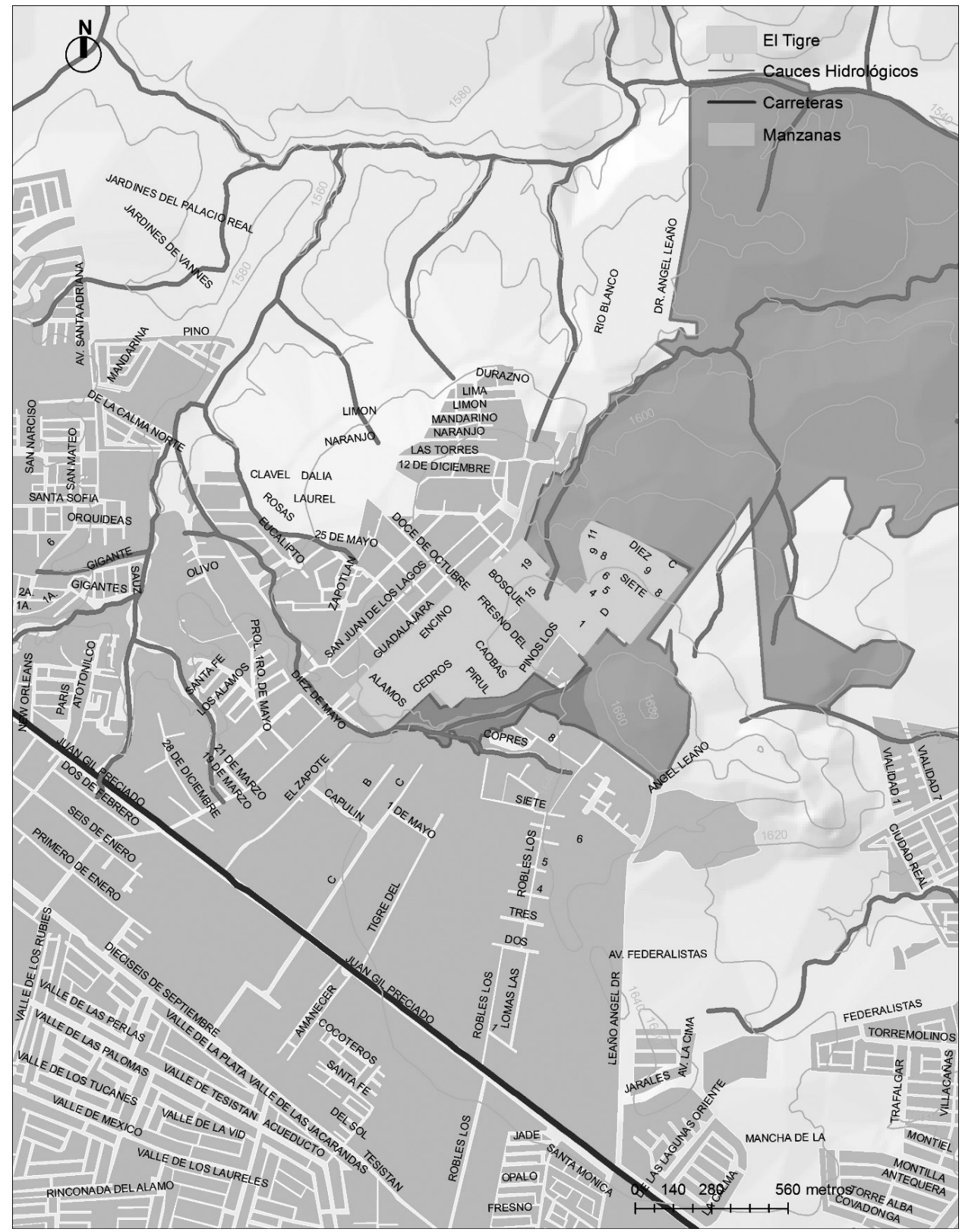

Fuente: Elaboración propia con datos del IITEJ, INEGI y la DGOP. 
Por la manera irregular de ocupación del suelo, progresivamente se han ido incorporando algunos servicios públicos. Actualmente, el $\mathrm{AHI}$ cuenta parcialmente con alumbrado público y el servicio de energía eléctrica proporcionada por la Comisión Federal de Electricidad (CFE), además de los servicios de recolección de basura y drenaje que le brinda el municipio, así como agua potable que les suministra el Sistema Intermunicipal de Agua Potable y Alcantarillado (SIAPA).

\section{Mapa 2. Servicios Públicos en El Tigre.}

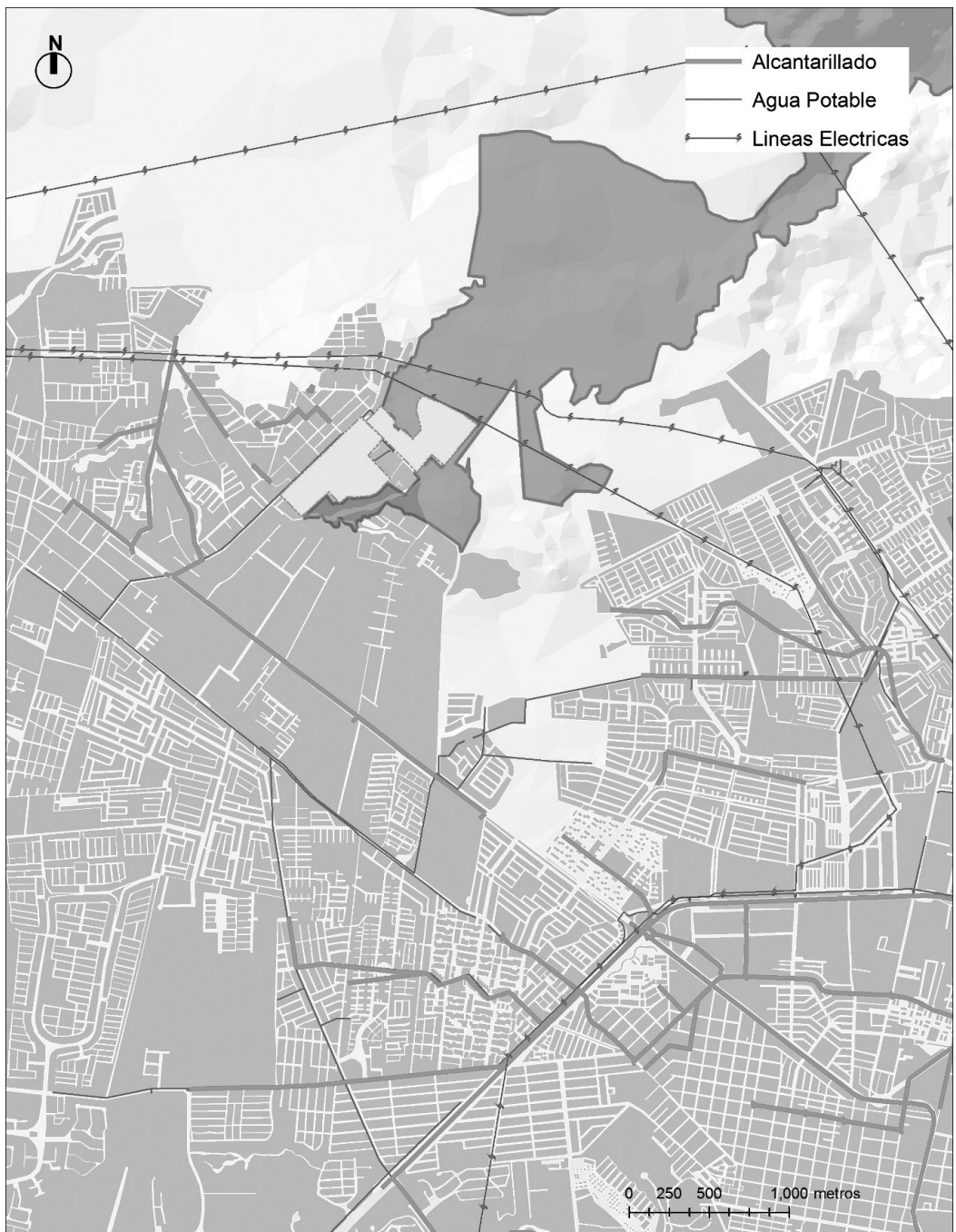

Fuente: Elaboración propia con datos del IITEJ, INEGI y la DGOP. 
Geográficamente el AHI se ubicó en una zona que para la década de los años ochenta, cuando se inició su ocupación, la zona fue considerada por la autoridad municipal escuetamente como un primer anillo de transición entre los usos de suelo urbano y rural. Sin embargo tanto por su topografía, caracterizada por un grado de pendiente suavemente inclinado y enclavada en una zona aledaña a barrancas y cauces hidrológicos de temporal, como por la posterior declaratoria de ANP a la que ya se ha hecho referencia previamente, la relación entre el AHI y su entorno natural se ha convertido en un factor clave para la sustentabilidad medio ambiental, toda vez que el espacio actualmente ocupado es percibido como una amenaza para la preservación del ANP.

Mapa 3. Cauces hidrológicos y riesgos en el Tigre.

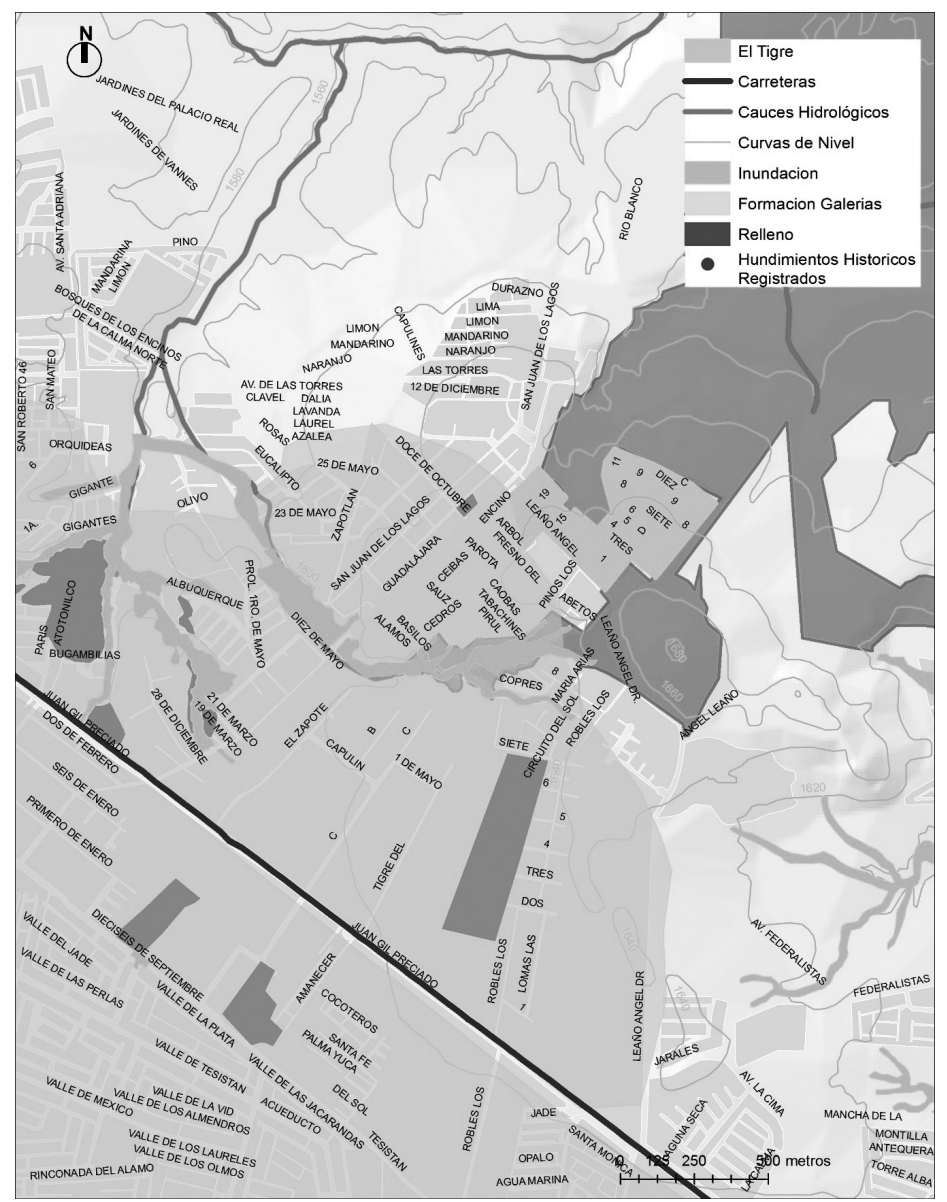

Fuente: Elaboración propia con datos del IITEJ, INEGI y la DGOP. 


\section{II.2 Los orígenes del problema: una fallida promoción inmobiliaria de interés público}

El desarrollo del fraccionamiento denominado El Tigre fue promovido por el Ayuntamiento de Zapopan en el año de 1986. Para ello, las autoridades municipales celebraron un Convenio de Gestión con la empresa constructora "Cordobesa, S. A. de C. V.", una figura jurídica prevista por la Ley Estatal de Fraccionamientos entonces vigente y que permitía la asociación entre autoridades municipales y empresas privadas con la finalidad de desarrollar vivienda de objetivo social.

Al amparo de dicho instrumento jurídico las partes se obligaron a realizar diversas acciones. El Ayuntamiento se obligó a gestionar cabalmente el desarrollo de dicho fraccionamiento en asociación con la empresa, comprometiéndose a exonerar el pago de los derechos derivados de la construcción del fraccionamiento, en tanto que la empresa constructora se obligó a realizar determinadas obras de infraestructura básica, tales como la red de drenaje, hidrantes públicos en los cruceros de las calles, trazo de calles, machuelos y el tratamiento primario de aguas residuales dejándolas aptas para el riego de áreas verdes, debiendo entregarlas al Ayuntamiento en un plazo de tres meses; además, la empresa debía entregar en donación al Ayuntamiento, el 15 por ciento de la superficie neta vendible para ser destinada a la instalación de servicios públicos y equipamiento urbano.

De manera previa a la urbanización del fraccionamiento, la empresa procedió a realizar la venta de lotes terreno a través de contratos preparatorios, es decir, contratos privados cuyo objeto fue la pre-venta de los lotes de terreno; sin embargo, finalmente la empresa incumplió con sus obligaciones adquiridas tanto con la autoridad municipal como con los compradores del futuro desarrollo habitacional.

Como se aprecia por el siguiente testimonio, los compradores defraudados en su gran mayoría los conformaron matrimonios jóvenes y sin hijos que, por aquellos años, buscaban terrenos a un precio accesible para eventualmente construir su casa:

Cuando mi esposa y yo andábamos buscando un terreno para hacer nuestra casa, buscamos primero cerca del Centro de Guadalajara porque ahí trabajábamos los dos. Mis papás son del barrio de Analco, entonces buscamos por esa zona. Luego un amigo nos comentó que si queríamos comprar barato teníamos que buscar fuera del "peri" [se refiere al Anillo Periférico Manuel 
Gómez Morín]. Dimos con estos terrenos que, por el proyecto que traían en planos, se nos hizo bonito. ¡lmagínese su casa a un lado del bosque!, con aire puro, y pues si estaba algo lejos pero yo tenía carro, entonces no estaba tan complicado. Y pues la verdad no fue tan complicado comprar, porque no se metían papeles a los bancos ni nada, nosotros dimos el enganche y nos citaron en la Presidencia -[Se refiere al Palacio Municipal de Zapopan]. Quien nos vendió nos dijo y nos mostró unos papeles donde venía que le estábamos comprando a la empresa y al municipio (Entrevista a vecino, 4/05/2014).

Al transcurrir el tiempo, los adquirientes de un Lote de terreno fueron construyendo sus viviendas bajo el esquema de autoconstrucción, sin contar con licencia o permiso emitido por la Dirección General de Obras Públicas (DGOP en lo sucesivo), toda vez que no contaban con un título de propiedad que acreditara la legal tenencia de la tierra, condición indispensable para efectos de tramitar cualquier tipo de autorización para edificar. De acuerdo con algunos testimonios, la responsabilidad se fue diluyendo entre la autoridad municipal y la empresa:

Estuvimos a vuelta y vuelta haya a la Curva [se refiere a la DGOP], pero nada. Íbamos con la inmobiliaria y nos decía que estaban tramitando una licencia general, pero nunca nos dijeron nada. En ese entonces, yo tenía ahorrado un dinero y si no construía me lo iba a gastar en cualquier cosa y así empezamos a construir. $Y$ no fui el único, como 15 empezamos al mismo tiempo y nunca nos dijeron nada (Entrevista a vecino, 4/05/2014).

La situación de indefinición jurídica tanto de los procesos de adquisición de la propiedad como las posteriores obras de edificación promovidas por los pobladores se mantuvo por varios años.

Es preciso subrayar que en el plano normativo, la obligación del Estado para intervenir en la planeación y regulación de la fundación, conservación, mejoramiento y crecimiento de los asentamientos humanos se incorporó formalmente hasta el año de 1992 con la reforma constitucional que se promovió al artículo $27,{ }^{5}$ referente normativo primigenio respecto de los regímenes del uso y explotación de las tierras.

Con el propósito de fomentar el desarrollo equilibrado del país y mejorar las condiciones de vida de la población rural y urbana, al amparo de la referida reforma constitucional fue promulgada la Ley General de Asentamiento Humanos un año después, con lo que se es-

\footnotetext{
${ }^{5}$ Reforma publicada en el Diario Oficial de la Federación del 6 de enero de 1992.
} 
tableció un régimen de concurrencia que dejó en plena libertad de los poderes legislativos estatales la competencia relativa al ordenamiento territorial de los asentamientos humanos y del desarrollo urbano de los centros de población.

En el caso de Jalisco la promulgación de la Ley de Desarrollo Urbano ocurrió en julio de 1993, prácticamente el mismo año que la Ley General ya referida.

\section{II.3 El proceso de regularización de EI Tigre I.}

La legislación estatal recién aprobada abrió la posibilidad para el establecimiento de programas que formalizaran el uso habitacional de predios interurbanos donde existían los Asentamientos Humanos Irregulares. ${ }^{6}$ No obstante, la legislación no dispuso con claridad las bases que permitieran hacer efectivos dichos programas de regularización.

Fue hasta el año de 1997 que el Congreso del Estado de Jalisco emitió el 26 de septiembre de 1997, el Decreto número 16664 que estableció los procedimientos para que los municipios pudieran operar la regularización de asentamientos humanos en predios o fraccionamientos urbanos y rurales de propiedad privada.

En virtud de dicho Decreto, las 466 familias que habitaban en la zona decidieron promover, hacia finales de la década de los años noventa, su regularización ante el Municipio de Zapopan, a través de la DGOP. De acuerdo con la información generada por la DGOP a través del levantamiento topográfico necesario para iniciar con el procedimiento administrativo correspondiente, en 1999 el AHI estaba integrado por 550 Lotes de terreno, ubicados en una superficie total de 520 mil 513 metros cuadrados. Sin embargo, dicha dependencia detectó que del total de la superficie urbanizada, 366 mil 377 metros cuadrados se ubicaban en un polígono de propiedad pública ${ }^{7}$ y el resto, 154 mil 136 metros cuadrados únicamente reunían las condiciones para su regularización

\footnotetext{
${ }^{6}$ Dos fueron los criterios predominantes fijados por la Ley: el primero fue la incorporación al suelo urbano, lo cual supuso la obligación por parte del municipio de dotar de infraestructura urbana necesaria para la prestación de los servicios públicos municipales. El segundo criterio fue la legal tenencia de la tierra, con base en el principio rector de la posesión como propietario, de buena fe en el momento de la adquisición, pacífica, continua y públicamente, de manera similar a la prescripción adquisitiva.

${ }^{7}$ Con fecha 7 de noviembre de 1988, el Municipio de Zapopan, Jalisco recibió por concepto de dona-
} 
al localizarse sobre el polígono de propiedad privada.

Bajo tales circunstancias, fue necesario circunscribir el procedimiento de regularización a los Lotes de terreno ubicados en el polígono de propiedad privada. De hecho, el fraccionamiento fue renombrado como "El Trigre I" para distinguirlo del resto de los Lotes ubicados en propiedad pública. La siguiente gráfica se ilustra el flujo procesal del procedimiento administrativo de regularización que se siguió, de conformidad con las etapas establecidas por el Decreto $17114^{8}$ del Congreso del Estado:

\section{Grafica 2. Flujograma del Proceso de Regularización de Asenta- mientos Humanos Irregulares.}

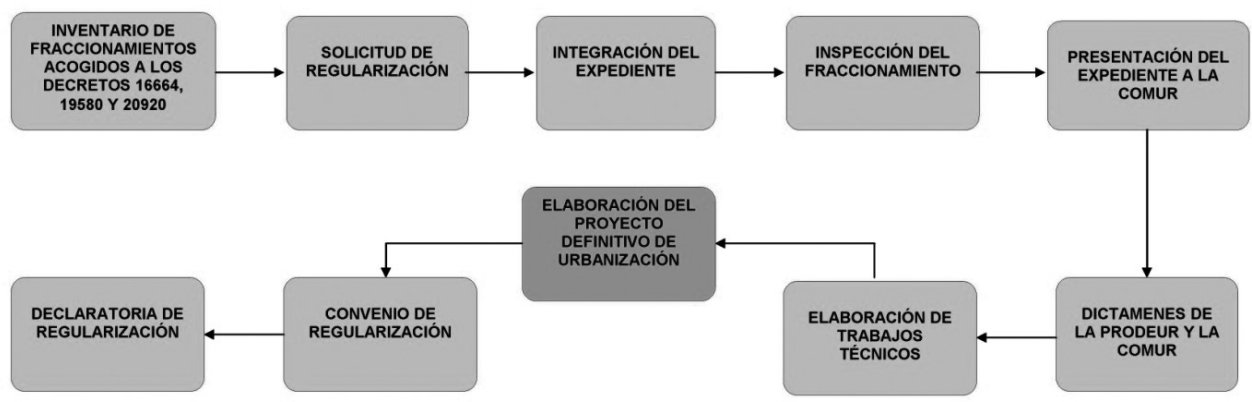

Fuente: Consejo Municipal de Regularización del Municipio de Zapopan, Jalisco.

Bajo este procedimiento, el Ayuntamiento de Zapopan regularizó la tenencia de la tierra de 305 Lotes de terreno que conforman ahora el fraccionamiento Colinas de los Robles, mediante un dictamen de procedencia emitido el 20 de agosto de 2001. De esta manera concluyó un auténtico calvario para algunos de los pobladores que, de acuerdo con algunos testimonios, mostraban una actitud más bien escéptica:

Recuerdo que entre los vecinos tuvimos varias platicas, porque al final todos teníamos el mismo problema, habíamos construido sin permiso y no teníamos papeles legales, entonces no podíamos vender, ni hacer nada, recuerdo que en una de las juntas de vecinos el presidente de colonos nos dijo que había

ción y en cumplimiento a lo establecido por la Ley Estatal de Fraccionamientos, de la empresa denominada Lomas de Tesistán, S.A. de C.V. una superficie aproximada de 366,377.00 metros cuadrados. ${ }^{8}$ Dicho decreto fue emitido el 23 de diciembre de $1997 \mathrm{~N}$. de A. 
una solución y por ahí platico con nosotros un funcionario de zapopan, nos explicó de un programa nuevo y nos dejó una lista de requisitos, al principio nos dio desconfianza, pero recuerdo que seguimos teniendo juntas, todos los domingos, hasta que nos organizamos bien y arrancamos el trámite (Entrevista a vecino, 4/05/2014).

Al momento de su regularización, el nuevo fraccionamiento contaba con la infraestructura urbana y los servicios púbicos a los que ya se hizo referencia en la sección previa, por lo que el nuevo Convenio de urbanización se limitó únicamente a la incorporación de áreas verdes y espacios de esparcimiento cívico, además del mantenimiento a la infraestructura ya existente.

\section{II.4 El intento fallido de regularización de El Tigre II.}

Entre tanto, al conjunto de Lotes de terreno localizados sobre la superficie identificada como de dominio público se denominó como "El Tigre II" para distinguirlos de aquellos que habían sido debidamente regularizados. Como se apuntó previamente, la promoción del fraccionamiento por objetivo social se enfrentó a una serie de incumplimientos tanto por parte de la constructora como por parte de las autoridades municipales. Entre las dificultades que se enfrentaron durante el proceso de urbanización, destaca precisamente una serie de señalamientos y sanciones realizadas por la autoridad municipal sobre aquellas obras de urbanización que afectaron una importante área arbolada, sin disponer de las autorizaciones correspondientes por parte de la Dirección de Ecología del Municipio.

Tal circunstancia provocó que el proceso de urbanización se detuviera, al menos formalmente, porque en la realidad se comenzó a gestar una serie de acuerdos no escritos que, de manera extraoficial, hizo posible que se fueran ocupando algunos predios colindantes a la superficie cuya propiedad eventualmente sería transferida al municipio por parte de la empresa inmobiliaria Lomas de Tesistán.

El siguiente testimonio ilustra las condiciones de incertidumbre en las que se encontraron quienes se aventuraron a comprar terrenos en esta franja aledaña a lo que posteriormente sería reconocida como zona de amortiguamiento del ANP.

Cuando nosotros íbamos al municipio nos decían que no podíamos fincar que porque había broncas con los terrenos y que la empresa no se había hecho 
responsable, y que no sé qué tantas cosas, pero que no nos iban a dar permiso. Íbamos a la empresa y lo mismo: que el municipio no soltaba el permiso y que estaban en negociación y que iban a cambiar unos terrenos que porque en unos no se podía y en otros sí. ¡Total! que nos tuvieron, yo creo, que como dos años así. Y la puritita verdad es que no decíamos nada porque ni habíamos acabado de pagar pero si queríamos construir (Entrevista a vecino, 4/05/2014).

Al concretarse el proceso de escrituración de la donación realizada por parte de la empresa Lomas de Tesistán al municipio, el predio donado se encontraba ocupado por 245 familias que habían adquirido Lotes de terreno con la promotora de bienes raíces "Pasto Inmobiliaria, S.A.", que fungió como operadora de la empresa "Cordobesa, S. A. de C. V."

El supuesto que propició esta ocupación ilegal, de acuerdo con algunos testimonios, fue que se preveía una probable permuta de la propiedad privada ubicada en la zona arbolada cuya urbanización no estaba permitida por algunos predios ubicados en la superficie de propiedad municipal susceptible de urbanización. En la práctica, la ocupación se fue concretando con el tiempo sin que se llevara a cabo ningún tipo de permuta que resolviera la situación jurídica sobre los terrenos ocupados.

Entre los años 2004 y 2006, las autoridades municipales, a través de la Dirección de Reservas Territoriales adscrita a la DGOP, promovieron la realización de un censo de aquellos ocupantes quienes acreditaron haber "adquirido" y "pagado" un lote, sobre el cual se precisó su ubicación y le fue asignado un valor estimado por parte de la Dirección de Catastro Municipal, como condición necesaria ante una eventual solución para los pobladores y que se llevaría a cabo de manera independiente al proceso de regularización realizado a través del Consejo Municipal de Regularización del Municipio de Zapopan (Cfr. Gráfica 2).

Una vez preparados los expedientes correspondientes, el proceso no se logró concretar y ni siquiera se culminó con el proceso de integración formal para el correspondiente estudio del caso por parte del Ayuntamiento, en virtud de que los vecinos, quienes previamente habían solicitado formalmente la regularización del fraccionamiento a través de su representante, finalmente no estuvieron de acuerdo con la propuesta presentada por la DGOP y que consistió en desincorporar del dominio público los inmuebles como paso previo para una posterior venta directa de los terrenos a precios accesibles a sus 
ocupantes. El motivo del rechazo por parte de los vecinos fue ellos ya habían "adquirido" y "pagado" previamente por los terrenos.

De acuerdo con algunos testimonios, el asunto recobró un nuevo aliento a raíz de los incentivos políticos derivados de la competencia electoral de 2009:

Cuando estuvo Vielma de Presidente, habían venido en campaña varios Regidores y nos dijeron que nos iban a ayudar. El primer día en que entraron, nosotros mandamos unos escritos y Anselmo [Se refiere a Anselmo Cruz Burgos, Presidente de la Asociación Vecinal el Tigre II], estuvo yendo pues a pedir que nos hicieran caso. Algunos si tenemos drenaje pero otros no, no tenemos canchas deportivas ni calles y pues ni cómo hacerle porque siempre terminan diciéndonos que los terrenos son del municipio y que no nos van a dar servicios hasta que no se regularice, pero pues ya llevamos más de 20 años así (Entrevista a Vecino, 5/06/2014)

Con la alternancia partidaria ocurrida en 2009 , las autoridades municipales electas para el periodo 2010-2012, decidieron retomar el asunto. ${ }^{9}$ A diferencia de ocasiones anteriores, en este caso se propuso restablecer el diálogo y el proceso de negociación con los ocupantes del fraccionamiento, lo cual derivó en una serie de reuniones que se Ilevaron a cabo tanto en las inmediaciones del AHI como a través de mesas de trabajo formalmente establecidas para tal efecto. La atención de la situación jurídica irregular se estableció como un asunto de la mayor prioridad para los actores involucrados, toda vez que desde la perspectiva de los ocupantes del fraccionamiento irregular, ellos han ejercido la posición sobre el predio municipal por un periodo muy prolongado de tiempo (más de 20 años), dicha ocupación ha sido de manera pacífica y pública, mediante adquisiciones y cesiones de derechos de propiedad de los lotes que se efectuaron entre particulares, a partir de la base de buena fe y la presunta calidad de propietarios. Que la escrituración a su favor no ha sido posible en virtud de la existencia de la escritura pública a favor del Municipio, lo cual ha afectado de manera considerable su patrimonio que fue realizado con mucho esfuerzo y recursos propios.

Como resultado del proceso de diálogo y negociación, los integrantes del Ayuntamiento optaron por establecer un Programa de Apoyo Financiero para los habitantes del fraccionamiento El Tigre II.

\footnotetext{
${ }^{9} \mathrm{El}$ entonces presidente municipal electo, Héctor Vielma Ordóñez y los regidores Salvador Rizo Castelo, María Sofía Valencia Abundis, Karla Torres Cervantes y Lourdes Arellano Aguilera presentaron una nueva iniciativa ante el Pleno del Ayuntamiento. N. de A.
} 
En el marco de dicho programa, las autoridades municipales se plantearon llevar a cabo la actualización del Censo de hogares realizado años atrás, con el propósito de determinar a las personas que eventualmente podrían ser beneficiarias.

Entre los criterios fijados para la ejecución del referido Programa, destaca el que las personas debían acreditar además de la ocupación de una fracción del predio identificado como de propiedad municipal, la adquisición correspondiente que haya dado origen a su condición irregular.

Además, las personas censadas debían presentar a las autoridades municipales una carta en la que manifestaran su intención de compra. Se determinó que el precio de venta por metro cuadrado se determinaría con base en la realización de un avalúo que debía realizar un perito con reconocimiento oficial para tal efecto. El precio así determinado, sería considerado como el precio mínimo de venta y correspondería al valor catastral correspondiente al año en que se llevara a cabo la operación.

Otras condiciones relativas establecieron que los ocupantes de los predios podrían realizar los pagos derivados de la venta en un plazo de 30 años, contados a partir de la firma de la respectiva escritura de propiedad. Los pagos podrían ser mensuales y el costo total del valor del inmueble podía ser liquidado de manera anticipada, en orden a las posibilidades económicas de los compradores. En el caso de las personas que optaran por adherirse al Programa de Financiamiento, la operación de compraventa se llevaría a cabo con reservar de dominio.

Se estableció que el costo de las escrituras sería cubierto por los ocupantes y para tal efecto, se daría aviso al Colegio de Notarios del Estado de Jalisco a fin de recibir su apoyo para darle un tratamiento especial a la escrituración. Por parte de las autoridades municipales, se ofreció el apoyo para asumir los costos relativos a la subdivisión de predios y el levantamiento topográfico respectivo.

Como medidas preparatorias para la ejecución del referido Programa, la autoridad municipal llevó a cabo una serie de acciones necesarias para la desincorporación del dominio público la superficie afectada. Para ello, fue necesario subdividir del predio municipal el polígono correspondiente al fraccionamiento. Lo anterior supuso segregar del total de los 366 mil 377 metros cuadrados de la superficie 
de propiedad municipal, alrededor de 63 mil 998 metros cuadrados que corresponden al fraccionamiento El Tigre II.

Cabe precisarse que de la totalidad de la superficie estimada, únicamente serían desincorporados los Lotes de los ocupantes que hubiesen acreditado ser compradores de buena fe y contar con la posesión, quedando la superficie de vialidades bajo el dominio público del municipio. Los predios identificados con conflictos legales serían beneficiados por el Programa hasta la resolución judicial correspondiente.

Se contempló además que la Asociación de Vecinos formalmente ratificada y constituida debería celebrar el Convenio respectivo a fin de ejecutar las obras de infraestructura faltantes a través de la Comisión Municipal de Regularización.

Los trabajos preparatorios y las acciones emprendidas por la DGOP en el marco del Programa fueron concluidos en agosto de 2011. En consecuencia, el valor por metro cuadrado de terreno susceptible de ser desincorporado quedó establecido por la Dirección de Catastro en razón de 760 pesos.

Evidentemente la reacción de los probables beneficiarios fue de total rechazo por estimar que dicho precio resultaba a todas luces excesivo y desproporcionado a sus posibilidades económicas por lo que el referido Programa de Apoyo Financiero fue prácticamente cancelado.

Los vecinos por su parte, decidieron formalizar una queja ante la Comisión Estatal de Derechos Humanos, a través del presidente de la asociación vecinal. ${ }^{10}$ Esta iniciativa derivó en una senda recomendación, la número 5/2014, emitida por el titular de la Comisión de Derechos Humanos el 14 de febrero de 2014. Dicha resolución no sólo contempló recomendaciones a efecto de que se retomara el proceso para resolver lo relativo a la tenencia de la tierra y se escucharan los argumentos señalados en la propia Recomendación, así como las propuestas de los agraviados, sino que además se consideraron otras recomendaciones tendientes a la incorporación de servicios públicos, espacios de esparcimiento y medidas precautorias apelando a la protección de los derechos ambientales, a la salud y a una vida digna de

${ }^{10}$ La queja correspondiente quedó registrada ante la autoridad competente con el expediente número 2638/2013/II. 
los agraviados y los pobladores de las colonias aledañas.

Como lo refiere el siguiente testimonio, los vecinos continúan insistiendo, bajo la consigna de que 30 años de ocupación y la progresiva incorporación de servicios públicos de agua potable y energía eléctrica resulta prácticamente imposible para la administración municipal que se pueda revertir a favor del Municipio la posesión del inmueble:

Pues mire, la verdad es que tenemos casi 30 años aquí, gobiernos vienen y gobiernos van. No estamos bien, nos falta mucho pero ahí vamos paso a paso y no nos vamos salir de donde ya pagamos. Es nuestra casa, es nuestra colonia (Entrevista a vecino, 4/06/2014).

\section{A manera de conclusión}

La experiencia del caso de estudio presentado en este trabajo ofrece la oportunidad de múltiples lecturas y líneas de reflexión. Para efectos de este artículo, la historia muestra cómo la escasa claridad e insuficiencia normativa en materia urbana ha derivado en una grave incapacidad directiva por parte del gobierno municipal de Zapopan respecto a sus facultades inherentes al ordenamiento territorial.

En efecto, una idea comúnmente aceptada en los estudios de implementación de políticas alude a la capacidad de la legislación para estructurar la puesta en marcha de cualquier política pública (Aguilar, 1996:336). Si además, atendemos a la naturaleza regulatoria (Lowi, 1964 y 1972), de las políticas urbanas que las convierten en:

Una arena de conflicto y negociación entre grupos de poder, que el pluralismo explica muy bien. Se trata de una arena relativamente turbulenta, de intereses exclusivos y contrapuestos y contrapuestos de grupo, que se mueven en torno de una misma cuestión y que se ven obligados a coaliciones y/o transacciones de recíproca concesión (Aguilar, 1992:32).

La legislación juega un papel fundamental para estructurar la política urbana. El estudio de caso ilustra con claridad cómo la inexistencia o insuficiencia de la legislación en materia urbana motivó una sucesión de condicionantes contextuales que derivaron en la incapacidad e ineficacia directiva del gobierno municipal de Zapopan expresada como una "fragmentación de las decisiones y las acciones del gobier- 
no" (Aguilar, 2013:125). Tal condición provoca, como la historia aquí contada, que no pocas decisiones y acciones gubernamentales

Afectan de manera negativa la eficacia y calidad de la dirección gubernamental, en tanto numerosas oportunidades de mejora de vida social se pierden y muchos problemas sociales quedan irresueltos, agravándose nocivamente si el gobierno no actúa de forma integrada en la articulación de políticas y recursos, y en establecer formas de coordinación y asociación entre las entidades que lo integran y entre los gobiernos (Aguilar, 2013:126).

En particular, la ventana de oportunidad que supuso, al menos en principio, la promulgación de la reglamentación procesal emitida por el Congreso del Estado en materia de regularización, sólo contribuyó a evidenciar que la dinámica socioeconómica que motivó el problema de irregularidad había avanzado a tal grado, que fue imposible resolver el problema para la totalidad de los pobladores del otrora único fraccionamiento El Tigre.

Aguilar Villanueva, Luis F. Estudio introductorio y edición (1992). La hechura de las Políticas. México: Miguel Ángel Porrúa.

Estudio introductorio y edición (1996). La implementación de las Políticas. México: Miguel Ángel Porrúa.

(2013). "Gestión estratégica y gestión de calidad en los gobiernos metropolitanos". En Urquidez, Octavio et. al. (coords.). Metrópolis en movimiento. México: El Colegio de Jalisco, pp. 125-146.

Arias de la Mora, Roberto. Coordinador (2013). Coordinación metropolitana y gestión pública municipal. México: El Colegio de Jalisco.

Becker, Gary (1968). "Crime and Punishment: An Economic Approach", en Journal of Political Economy. $\mathrm{N}^{\circ} 76$.

\section{Bibliografía}


Brugé, Quim y Ricard Gomá, coords. (1998). Gobiernos locales y políticas públicas. Bienestar social, promoción económica y territorio. España: Ariel.

Caro Chaparro, Blanca Noelia, Leonardo A. Gatica Arreola y María del Rosario Ruiz Hernández (2013). "Polarización espacial y limitaciones en las políticas redistributivas. Los efectos de la democracia electoral y la competencia intragubernamental en zonas metropolitanas". En Arias de la Mora, Roberto (coord.). Coordinación metropolitana y gestión pública municipal. México: El Colegio de Jalisco, pp. 39-70.

Lowi, Th. (1964). "American Bussines and Public Policy Case Studies and Political Theory", en World Politics, XVI, pp. 677-715.

(1972). "Four Systems of Policy, Politics and Choice", en Public Adminitration Review, vol. 32, pp. 298-310.

Merino, Mauricio, et. al. (2010). Problemas, decisiones y soluciones: enfoques de política pública. México: FCE, CIDE.

Roemer, Andrés (1994). Introducción al análisis económico del derecho. México: ITAM, Sociedad Mexicana de Geografía y Estadística y FCE. 